\title{
Optical investigation of GaSb thin films grown on GaAs by metalorganic magnetron sputtering
}

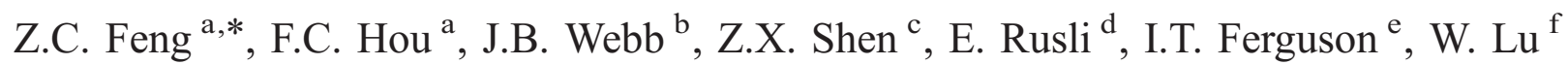 \\ ${ }^{\text {a }}$ Graduate Institute of Electro-Optical Engineering and Department of Electrical Engineering, National Taiwan University, Taipei, 106-17, Taiwan, ROC \\ ${ }^{\mathrm{b}}$ Institute for Microstructural Sciences, National Research Council Canada, Ottawa, Ontario, Canada K1A 0R6 \\ ${ }^{c}$ Division of Physics \& Applied Physics, School of Physical \& Mathematical Sciences, Nanyang Technological University, Singapore 63979, Singapore \\ d School of Electrical \& Electronic Engineering, Nanyang Technological University, Singapore 63979, Singapore \\ ${ }^{\mathrm{e}}$ School of Electrical \& Computer Engineering, Georgia Institute of Technology, Atlanta, GA 30332-0250, USA \\ ${ }^{\mathrm{f}}$ Department of Chemistry, Fisk University, Nashville, TN 37208, USA
}

Available online 13 July 2007

\begin{abstract}
Metalorganic magnetron sputtering (MOMS) technology has been applied to the growth of epitaxial GaSb layers on GaAs (001). Optical studies are performed on a series of $\mathrm{GaSb} / \mathrm{GaAs}$ samples grown under different growth conditions. Raman scattering measurements indicated the improvement of the crystalline quality of the GaSb thin film from the interface toward the surface with decreasing substrate growth temperature from $480{ }^{\circ} \mathrm{C}$ to $400{ }^{\circ} \mathrm{C}$. Fourier transform infrared (FTIR) reflectance revealed the possible existence of an intermixed GaSb-GaAs layer near the interface. In UV reflectance spectra, the shapes of the high energy transition bands were found to be associated with the GaSb film quality. (C) 2007 Elsevier B.V. All rights reserved.
\end{abstract}

Keywords: Metalorganic magnetron sputtering; Raman scattering; FTIR; UV reflectance

\section{Introduction}

The III-V compound semiconductor gallium antimonide $(\mathrm{GaSb})$ has in recent years attracted much attention as an important material for infrared (IR) optoelectronic and electronic device in the wavelength range $1-5 \mu \mathrm{m}[1-13]$. GaSb has an energy bandgap of $0.70 \mathrm{eV}(1.77 \mu \mathrm{m})$ at room temperature (RT) and $0.81 \mathrm{eV}(1.53 \mu \mathrm{m})$ at $4 \mathrm{~K}$ [14]. Its lattice constant of $6.0959 \AA$ at RT matches that of various ternary and quaternary compounds with band gaps covering a wide spectral range of $0.3-1.58 \mathrm{eV}$ $(0.8-4.3 \mu \mathrm{m})[11,14]$. The GaSb-InAs superlattice (SL) with the type-II band offset structure has shown special electronic properties with useful applications $[5,8,9]$. Type-II GaInAsSb$\mathrm{GaSb}$ heterojunctions and other GaSb-based quantum structures have played an important role in recent research and development of high power laser diodes and detectors operating in the mid-IR $2-5 \mu \mathrm{m}$ region $[15,16]$. Good epitaxial growth of $\mathrm{GaSb}$ on $\mathrm{GaAs}$ (001) is important for research and development [11,17]. Due to

\footnotetext{
* Corresponding author.

E-mail address: zcfeng@cc.ee.ntu.edu.tw (Z.C. Feng).
}

the lattice mismatch between $\mathrm{GaSb}$ and $\mathrm{GaAs}(\sim 7 \%)$, epilayers a few microns thick typically possess a high density of dislocations, and therefore, it has been essential to develop techniques to control film quality control and evolution [11,17].

Various growth techniques have been employed in the growth of GaSb on GaAs (001) [[11] and references therein], among which the major methods of molecular beam epitaxy (MBE) and metalorganic vapor phase epitaxy (MOVPE) have been emphasized in past years. However, new technologies are developing to challenge these two growth methods. The conventional solid sources in MBE can cause problems for the growth of materials with high vapour pressure. To overcome this difficulty, gaseous and metalorganic vapor sources have been added to MBE to achieve a marriage between MBE and MOVPE. This new growth technique, called metalorganic molecular beam epitaxy (MOMBE) [18] or chemical beam epitaxy (CBE) [19], combines the advantages of MBE and MOVPE, providing stable group V vapor beams for epitaxy. In another approach, we have developed a novel technology of metalorganic magnetron sputtering (MOMS) for the preparation of epitaxial InSb and Sb-based materials and microstructures [20-23]. Pulsed laser evaporation and epitaxy (PLEE) is another method, which avoids the use of 
Table 1

Sample information

\begin{tabular}{lllll}
\hline Sample no. & JJ061 & JJ058 & JJ059 & JJ062 \\
\hline$T_{\mathrm{s}}\left({ }^{\circ} \mathrm{C}\right)$ & 480 & 440 & 420 & 400 \\
GaSb growth rate $(\mu \mathrm{m} / \mathrm{h})$ & 1.05 & 0.45 & 0.40 & 0.40 \\
$d(\mu \mathrm{m})$ & 0.70 & 0.57 & 0.60 & 0.58 \\
\hline
\end{tabular}

$T_{\mathrm{s}}$ : substrate growth temperature $\left({ }^{\circ} \mathrm{C}\right)$.

$d$ : GaSb film thickness ( $\mu \mathrm{m})$.

the thermal or vapor sources [24]. Clearly, no single growth technique can hope to achieve optimal results for all materials systems. New techniques are being pursued to combine the advantages of various growth methods.

In this paper, we report on the epitaxial growth and optical characterization of GaSb thin films (less than $1 \mu \mathrm{m}$ thick) on GaAs (001) via MOMS. Usually, MBE growth of GaSb on GaAs (001) is performed in the temperature range of $500-600{ }^{\circ} \mathrm{C}[11]$, or lower, at $490{ }^{\circ} \mathrm{C}$ [17]. For the MOVPE growth of $\mathrm{GaSb}$ on GaAs (001), different temperature ranges were used, such as 560 $620^{\circ} \mathrm{C}$ [25] and $400-560^{\circ} \mathrm{C}$ [26]. In our MOMS growth process, lower substrate growth temperatures were employed and an optimum temperature was found to be close to $400{ }^{\circ} \mathrm{C}$. Detailed results of the optical characterization for MOMS grown $\mathrm{GaSb}$ on GaAs (001) in the temperature range $400-480{ }^{\circ} \mathrm{C}$ are presented.

\section{Experiment}

\subsection{Sample preparation}

The MOMS deposition system consists of an ultra-highvacuum (UHV) chamber with sample load-lock and planar magnetron sputter guns. The UHV system was cryogenically pumped to a base pressure of $\sim 10^{-7} \mathrm{~Pa}$ before deposition. The GaAs substrates were cleaned using a $\left(\mathrm{H}_{2} \mathrm{SO}_{4}: \mathrm{H}_{2} \mathrm{O}_{2}: \mathrm{H}_{2} \mathrm{O}=6: 1: 1\right)$ wet etch. Substrates were thermally bonded to an indirectly heated molybdenum holder using indium solder. The substrate temperature was monitored with a calibrated thermo-couple in close proximity to the rotating holder. DC reactive sputtering of highpurity polycrystalline $\mathrm{Sb}$ target was performed in the presence of metalorganic vapors of trimethylgallium (TMG). The TMG bubbler was held at $0{ }^{\circ} \mathrm{C}$. The getter-purified high-purity argon was introduced via a mass-flow controller to serve as the carrier gas to control the TMG flow rate. The total gas flow rate was maintained at $30 \mathrm{sccm}$ under a low deposition pressure of $\sim 0.4 \mathrm{~Pa}$. All growths were carried out in an antimony stabilized regime [20-23].

In the present study, thin $(0.5-0.7 \mu \mathrm{m}) \mathrm{GaSb}$ films were grown on GaAs (001) substrate with different substrate growth temperature, $T_{\mathrm{S}}$, between 400 and $480{ }^{\circ} \mathrm{C}$. These led to different growth rates as listed in Table 1 . Starting from a high $T_{\mathrm{S}}=480^{\circ} \mathrm{C}$, a growth rate of slightly higher than $1 \mu \mathrm{m} / \mathrm{h}$ was obtained. At higher $T_{\mathrm{S}}$, the thermal decomposition of metalorganic dominates. When $T_{\mathrm{S}}$ decreases, the thermal cracking of metalorganic is reduced and plasma induced decomposition of metalorganic becomes the dominant process, leading to a decrease of the growth rate. When $T_{\mathrm{S}}$ is lower than $430{ }^{\circ} \mathrm{C}$ the growth rate was saturated at a low rate of $0.40 \mu \mathrm{m} / \mathrm{h}$ [27] indicating the over- through domination of the plasma induced decomposition mechanism. After the growth, these experimental samples were examined by X-ray diffraction (XRD), scanning electron microscopy (SEM), Hall and optical absorption measurements [27].

\subsection{Materials characterization techniques}

In this paper Raman scattering, UV-Visible optical reflectance and Fourier transform infrared (FTIR) spectroscopy were employed to further investigate the material properties of MOMS grown GaSb on GaAs (001) and their dependence on substrate growth temperature.

Raman scattering was measured in the near back-scattering geometry with samples held at a low temperature dewar $(80 \mathrm{~K})$, or RT, and excited by an $\mathrm{Ar}^{+}$laser with a focused spot size $<0.3 \mathrm{~mm}$. The scattered light was dispersed by a triple spectrometer and detected by a sensitive optical multichannel analyzer with resolutions of $2-3 \mathrm{~cm}^{-1}$ [28]. Fourier transform infrared (FTIR) reflectivity measurements in the wavenumber range of 20-250 or 20-500 $\mathrm{cm}^{-1}$ were done using a GrubbParsons Fourier spectrometer with a Golay detector, at temperatures of 300 and $80 \mathrm{~K}$. The reflection coefficient was determined as the ratio of the intensity of the light reflected from the sample against that reflected from a reference mirror made of coin silver with about 98\% reflectance [21]. Optical reflectance was measured using a Hitachi U-3410 spectrophotometer in the wavelength range between 190 and $2500 \mathrm{~nm}$.

\section{Results and discussion}

\subsection{Raman scattering}

Fig. 1 shows comparative RT Raman spectra of three MOMS grown $\mathrm{GaSb} / \mathrm{GaAs}(001)$ and a bulk GaSb. The GaSb longitudinal

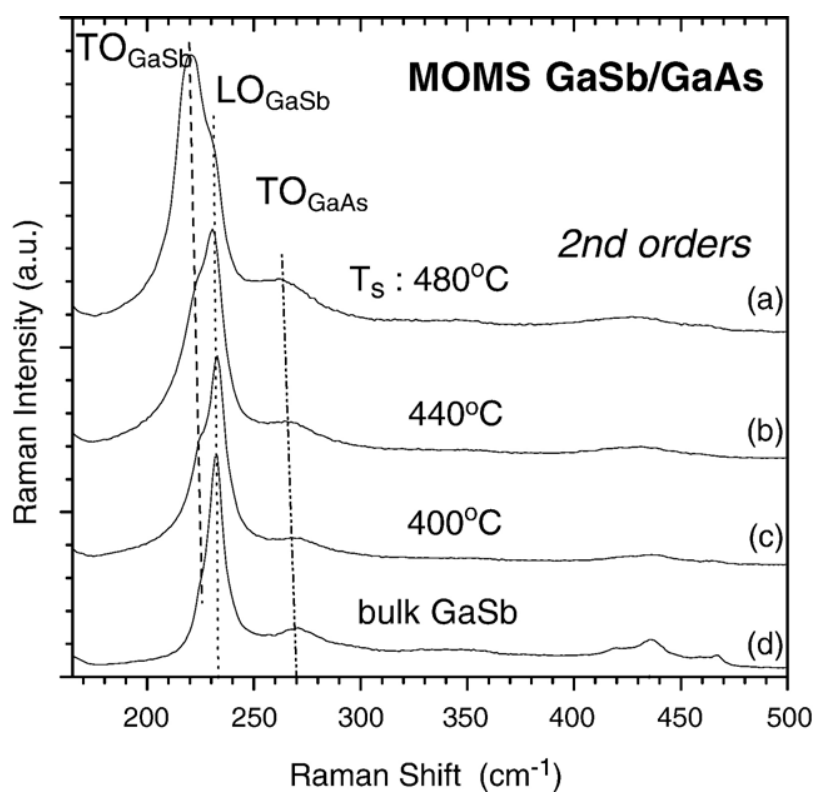

Fig. 1. Raman spectra from three MOMS-grown GaSb/GaAs (001) grown at substrate temperature of (a) $480^{\circ} \mathrm{C}$, (b) $440{ }^{\circ} \mathrm{C}$ and (c) $400^{\circ} \mathrm{C}$, and (d) a bulk GaSb. 


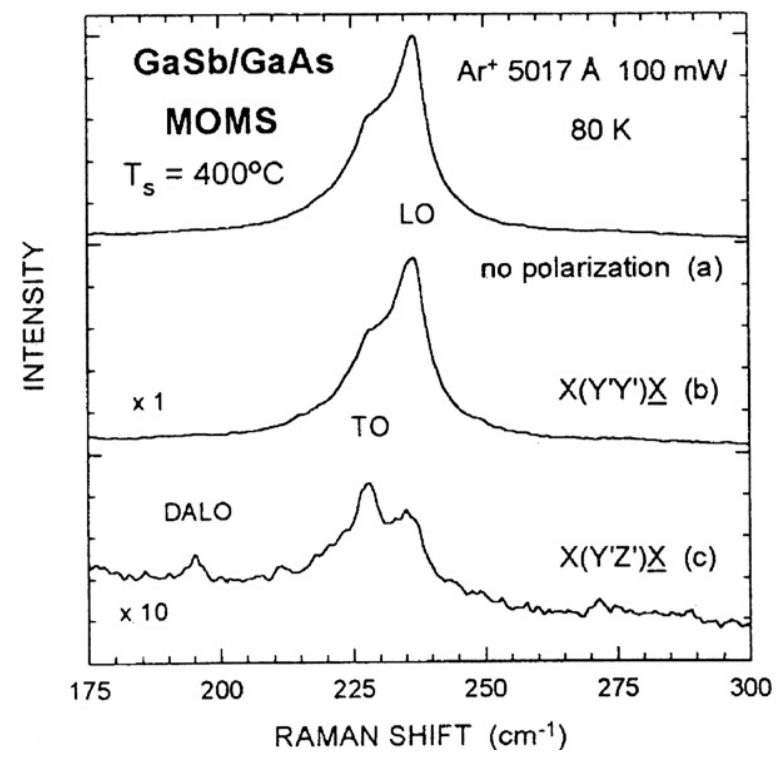

Fig. 2. Raman spectra from a MOMS-grown $\mathrm{GaSb} / \mathrm{GaAs}$ (100) with $T_{\mathrm{s}}=400{ }^{\circ} \mathrm{C}$, measured under different polarization configurations: (a) no polarization, (b) $X\left(Y^{\prime} Y^{\prime}\right) X$ and (c) $X\left(Y^{\prime} Z^{\prime}\right) X$.

optical (LO) and transverse optical (TO) phonon mode at the center of Brillioun zone were detected. According to Raman selection rules, the LO phonon mode is allowed and TO is forbidden for the (001) orientation of a zincblende crystal [28]. Because these $\mathrm{GaSb}$ films are thinner than $0.6 \mu \mathrm{m}$, there exist a

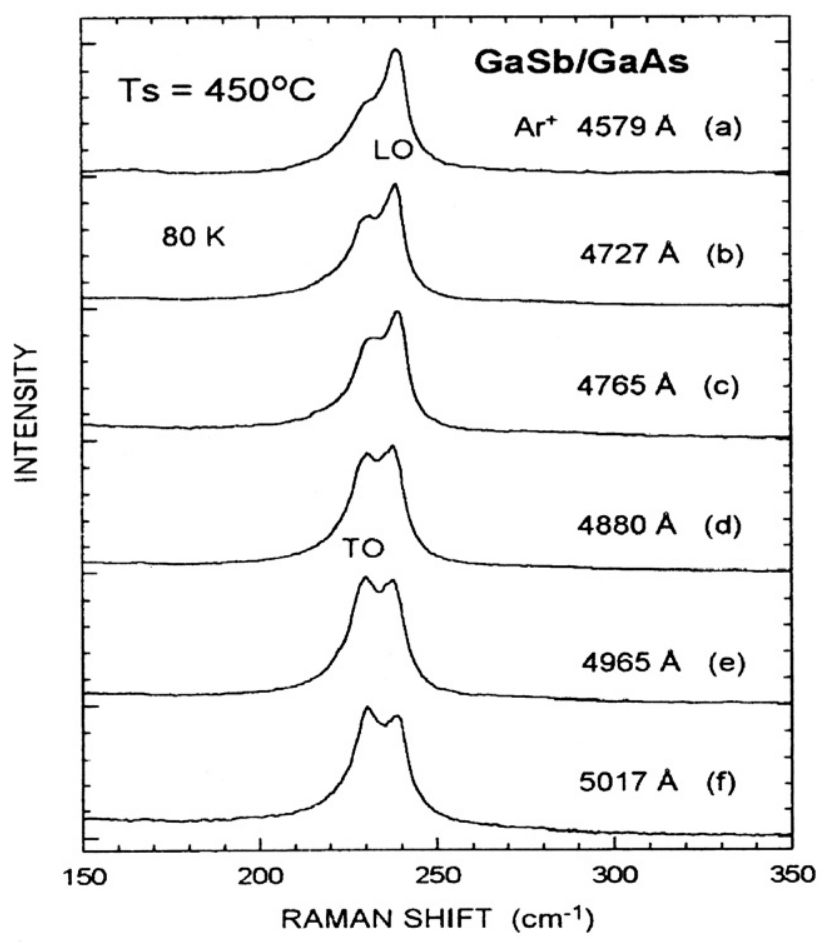

Fig. 3. Raman spectra from a MOMS-grown GaSb on GaAs (100) with $T_{\mathrm{s}}=480{ }^{\circ} \mathrm{C}$, under different excitation wavelengths between 4579 and $5017 \AA$ from an $\mathrm{Ar}^{+}$laser.

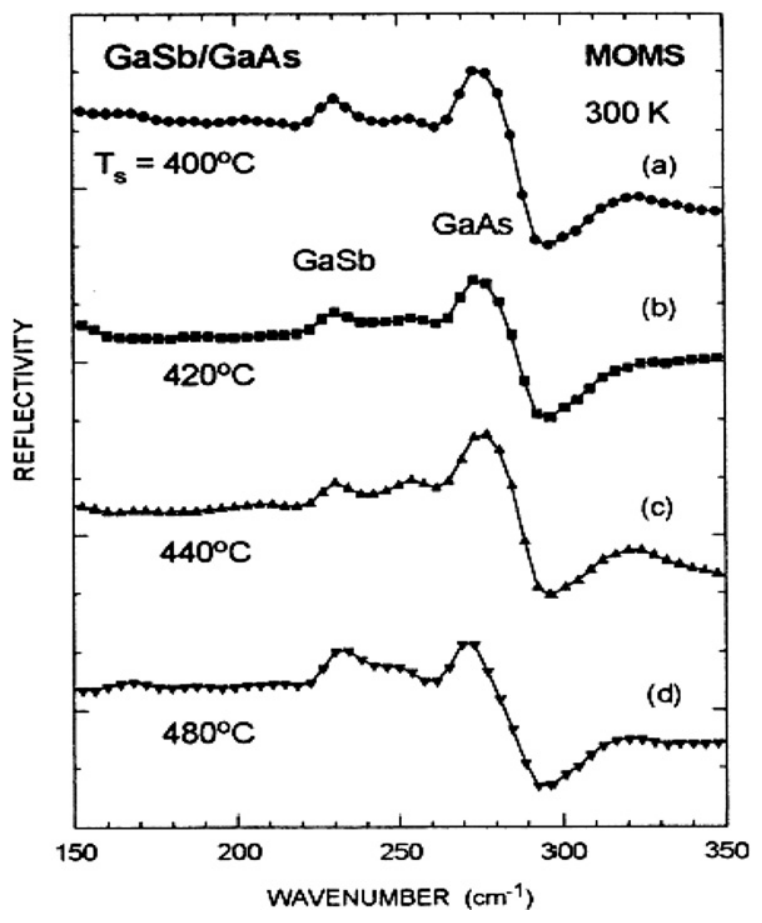

Fig. 4. FTIR reflectivity spectra from four MOMS-grown $\mathrm{GaSb} / \mathrm{GaAs}(100)$ under different substrate growth temperature of (a) $400{ }^{\circ} \mathrm{C}$, (b) $420^{\circ} \mathrm{C}$, (c) $440{ }^{\circ} \mathrm{C}$ and (d) $480{ }^{\circ} \mathrm{C}$.

high density of dislocations in the films [17], which breaks the symmetry and leads to the appearance of the forbidden TO modes.

The LO and TO modes can be distinguished by polarization measurements as shown in Fig. 2, where $X$ is along the (100) axis and $X$ is its reversed direction, $Y^{\prime}$ is along (011) and $Z^{\prime}$ is along $(011)$. Obeying the selection rule for a $(100)$ surface from a zincblende crystal [28], the LO mode is allowed in the $X\left(Y^{\prime} Y^{\prime}\right)$ $X$ configuration and forbidden in $X\left(Y^{\prime} Z^{\prime}\right) X$, while the TO mode is allowed in $X\left(Y^{\prime} Z^{\prime}\right) X$ and forbidden in $\mathrm{X}\left(\mathrm{Y}^{\prime} \mathrm{Y}^{\prime}\right) X$, which confirms the assignments for LO and TO modes. The mode appeared at $195 \mathrm{~cm}^{-1}$ in $X\left(Y^{\prime} Z^{\prime}\right) X$ may be due to the defect activated longitudinal optical (DALO) phonon, related to defects in the sample.

As seen in Fig. 1(a), the "forbidden" TO mode is dominant for samples grown at $T_{\mathrm{s}}=480{ }^{\circ} \mathrm{C}$. As $T_{\mathrm{s}}$ decreases to $440{ }^{\circ} \mathrm{C}$, in Fig. 1(b), the LO mode intensity increases with respect to the TO mode. At $T_{\mathrm{s}}=400{ }^{\circ} \mathrm{C}$, the allowed LO mode is dominant with a weak shoulder, "forbidden" TO mode, Fig. 1(c). This indicates that the film quality improves with decreasing substrate growth temperature, which is consistent to the XRD result showing a narrowing of the (004) GaSb peak as decreasing $T_{\mathrm{s}}$ (data not shown here). But, we found that we could not grow an epitaxial film for $\mathrm{T}_{\mathrm{s}}<400{ }^{\circ} \mathrm{C}$. Therefore, the optimum substrate temperature for growth of epitaxial $\mathrm{GaSb}$ thin films using the MOMS technique is about $400{ }^{\circ} \mathrm{C}$.

Fig. 3 shows Raman spectra from a MOMS-grown $\mathrm{GaSb} /$ GaAs sample made at a high substrate temperature $480{ }^{\circ} \mathrm{C}$, measured under different excitation wavelengths between 4579 and $5017 \AA$ from an $\mathrm{Ar}^{+}$laser. As seen, with decreasing excitation wavelength or penetration depth from Fig. 3(f) to (a), 


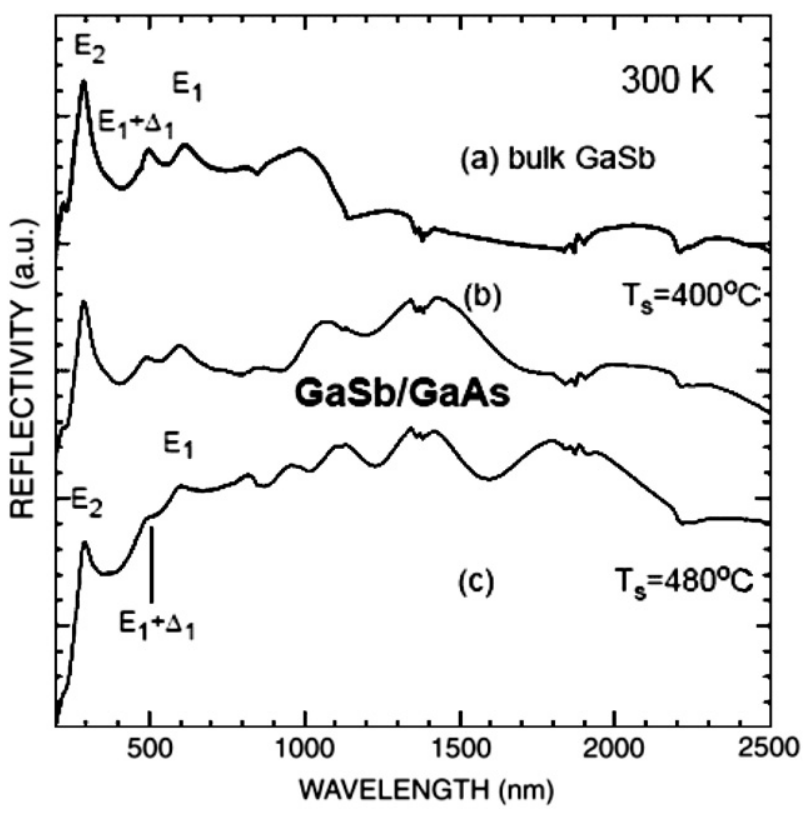

Fig. 5. UV-IR optical reflectivity spectra from (a) bulk GaSb wafer and MOMSgrown $\mathrm{GaSb} / \mathrm{GaAs}$ samples grown at (b) $T_{\mathrm{s}}=400{ }^{\circ} \mathrm{C}$ and (c) $T_{\mathrm{s}}=480{ }^{\circ} \mathrm{C}$.

the forbidden TO mode decreases in intensity with respect to the allowed LO mode, indicating the development of the crystalline perfect towards the surface.

\subsection{FTIR reflectance and interface mode}

Because visible laser light penetrates only tens of nanometer into $\mathrm{GaSb}$, Raman scattering cannot probe the $\mathrm{GaSb} / \mathrm{GaAs}$ interface directly. Instead, we used infrared light which can penetrate the entire $\mathrm{GaSb}$ layer to probe the $\mathrm{GaSb} / \mathrm{GaAs}$ interface. Fig. 4 exhibits FTIR reflectivity spectra for this series of MOMS-grown $\mathrm{GaSb} / \mathrm{GaAs}$ at different $T_{\mathrm{s}}$. There exist two major bands, one of near $270 \mathrm{~cm}^{-1}$ due to the TO phonon vibration from GaAs substrate [29] and another one of near $230 \mathrm{~cm}^{-1}$ from the TO mode of GaSb film [21,29]. In addition, a third mode appears at about $254 \mathrm{~cm}^{-1}$ between these two major bands and develops with increasing $T_{\mathrm{s}}$. This third mode might be due to the existence of a GaAs-GaSb intermixed layer near the interface. It was varied with $T_{\mathrm{s}}$. Further study on this mode is needed.

\subsection{UV-VIS-NIR optical reflectance}

Optical reflectance spectra covering the ultraviolet to nearinfrared range 200-2500 $\mathrm{nm}$ have also been used to evaluate the $\mathrm{GaSb} / \mathrm{GaAs}$ samples, as displayed in Fig. 5, for two of our MOMS-grown samples and from a wafer of bulk GaSb, shown for comparison. The three reflectivity maxima between 200 and $700 \mathrm{~nm}$ represent the high energy GaSb $E_{1}, E_{1}+\Delta_{1}$ and $E_{2}$ band gaps. These peaks display similar heights and half-widths for the bulk sample and the epitaxial sample grown at $400{ }^{\circ} \mathrm{C}$. But they become flatter and less-well defined for the sample grown at $480{ }^{\circ} \mathrm{C}$. This can also be taken as an indication of lower sample quality at the higher growth temperature, consistent with our Raman and FTIR results. This might also be related to the poorer surface roughness from the sample grown at higher temperature. The UV-VIS-NIR optical reflectivity spectra for $\mathrm{GaSb} / \mathrm{GaAs}$ also exhibit some interference fringes in the wavelength range beyond $1000 \mathrm{~nm}$. These can also be used to determine the GaSb film thickness. The results are given in Table 1, which are consistent with the data obtained from scanning electron microscope (SEM) measurements by examining a cleaved edge [29].

\section{Conclusion}

Metalorganic magnetron sputtering (MOMS) technology has been applied to the growth of epitaxial thin GaSb layers on GaAs (100) with the film thickness less than $0.6 \mu \mathrm{m}$. Optical characterization has been performed on a series of $\mathrm{GaSb} / \mathrm{GaAs}$ epilayers grown under different conditions. The following significant results are obtained:

Raman scattering on MOMS-grown GaSb/GaAs (100) shows that the forbidden TO mode is dominant for the sample grown at high substrate growth temperature $\left(480{ }^{\circ} \mathrm{C}\right)$. Its intensity with respect to the allowed LO phonon mode decreases with decreasing $T_{\mathrm{s}}$ from $480{ }^{\circ} \mathrm{C}$ to $400{ }^{\circ} \mathrm{C}$. At $T_{\mathrm{s}}$ of $400{ }^{\circ} \mathrm{C}$, the LO mode dominates the spectrum. The TO appears as a weak shoulder and this occurs because of defects induced by lattice mismatch in these films much thinner than $1 \mu \mathrm{m}$.

Raman scattering indicates directly and clearly that the $\mathrm{GaSb}$ film quality improves with decreasing substrate growth temperature from $480{ }^{\circ} \mathrm{C}$ to $400{ }^{\circ} \mathrm{C}$.

Raman scattering with different laser excitation wavelengths indicates that the crystalline perfection of the GaSb thin film improves with vertical distance away from the interface and toward the surface.

The MOMS technique yields an optimum substrate growth temperature of $\sim 400{ }^{\circ} \mathrm{C}$, which is lower than the growth temperature used in MBE and MOCVD techniques.

A new mode near $254 \mathrm{~cm}^{-1}$ between the GaSb and GaAs TO modes was observed from FTIR reflectance, which might be related to the $\mathrm{GaSb}-\mathrm{GaAs}$ intermixed layer near the interface.

Growth at high temperature damps the $E_{1}$ and $E_{1}+\Delta_{1}$ electronic transition bands in the ultraviolet, and UV reflectance spectra can be used to monitor GaSb film quality. Interference fringes in the near infrared can be used to determine the film thicknesses.

These results on MOMO-grown $\mathrm{GaSb} / \mathrm{GaAs}$ will enhance our efforts in developing the MOMS technique for materials growth and help us understand both the growth mechanisms and the physics of these hetero-structures for IR applications. Further penetrative and qualitative analysis on Raman and IR spectra and correlation with SEM and XRD data will be made in the near future.

\section{Acknowledgements}

We acknowledge the help and supports from Profs. S. Perkowitz and S. H. Tang. The work was supported by funds at National Taiwan University from National Science Council of 
Republic of China, NSC 94-2215-E-002-019 and 95-2221-E002-118, and at Fisk University by the NSF (Grant No: HRD0420516) Center for Physics and Chemistry of Materials.

\section{References}

[1] Hyunjung Kim, E. Tarhan, G. Chen, A.K. Ramdas, M. Dean Sciacca, R.L. Gunshor, Semicond. Sci. Technol. 21 (2006) 1224.

[2] D. Kindl, P. Hubík, J. Krištofik, J.J. Mareš, E. Hulicius, J. Pangrác, K Melichar, Z.V. Výborný, J. Touškov', Semicond. Sci. Technol. 21 (2006) 180.

[3] O. Vigil-Galán, J.N. Ximello-Quiebras, J. Aguilar-Hernández, Gerardo Contreras-Puente, A. Cruz-Orea, J.G. Mendoza-Álvarez, J.A. CardonaBedoya, C.M. Ruiz, V. Bermúdez, Semicond. Sci. Technol. 21 (2006) 76.

[4] S.M. Kluth, J.D. Fitz Gerald, M.C. Ridgway, Appl. Phys. Lett. 86 (2006) 131920.

[5] Jian V. Li, Shun Lien Chuang, Eric M. Jackson, Edward Aifer, Appl. Phys. Lett. 85 (2004) 1984.

[6] M.P. Hanson, D.C. Driscoll, J.D. Zimmerman, A.C. Gossard, E.R. Brown, Appl. Phys. Lett. 85 (2004) 3110.

[7] Z.Y. Liu, D.A. Saulys, T.F. Kuech, Appl. Phys. Lett. 85 (2004) 4391.

[8] H.J. Haugan, F. Szmulowicz, G.J. Brown, K. Mahalingam, Appl. Phys. Lett. 84 (2004) 5410.

[9] Y. Wei, A. Gin, M. Razeghi, G.J. Brown, Appl. Phys. Lett. 80 (2002) 5410.

[10] F.M. Liu, L.D. Zhang, Semicond. Sci. Techol. 14 (1999) 710.

[11] P.S. Dutta, H.L. Bhat, V. Kumar, J. Appl. Phys. 81 (1997) 5821.

[12] A. Bignazzi, A. Bosacchi, R. Magnanini, J. Appl. Phys. 81 (1997) 7540.

[13] M. Gauneau, R. Chaplain, A. Rupert, Y. Toudic, R. Callec, J. Appl. Phys. 73 (1993) 2051.
[14] V. Swaminathan, A.T. Macrander, Materials Aspects of GaAs and InP Based Structures, Prentice Hall, New Jersey, 1991.

[15] M.P. Mikhailova, A.N. Titkov, Semicond. Sci. Technol. 9 (1994) 1279.

[16] G.W. Turner, H.K. Choi, M.J. Manfra, M.K. Connors, in: M.O. Manasreh, T.H. Myers, F.H. Julien (Eds.), Infrared Applications of SemiconductorsMaterials, Processing and Devices, Mat. Res. Soc. Symp. Proc., vol. 450, Materials Research Society, Pittsburgh, 1997, pp. 3-12.

[17] P.M. Thibado, B.R. Bennett, M.E. Twigg, B.V. Shanabrook, L.J. Whitman, J. Vac. Sci. Technol., A 14 (1996) 885.

[18] W. Zhou, K. Uesugi, I. Suemune, Appl. Phys. Lett. 83 (2003) 1992.

[19] J.O. Maclean, T. Martin, M.R. Houlton, P.D.J. Calcott, S.G. Ayling, K.P. Hilton, S.A. Rushworth, L.M. Smith, Appl. Phys. Lett. 80 (2002) 914.

[20] J.B. Webb, R. Rousina, in: Z.C. Feng (Ed.), Semiconductor Interfaces and Microstructures, World Scientific Publishing, Singapore, 1992, p. 199.

[21] M. Macler, Z.C. Feng, S. Perkowitz, R. Rousina, J.B. Webb, Phys. Rev., B 46 (1992) 6902.

[22] J.B. Webb, D.J. Lockwood, V.P. Gnezdilov, J. Cryst. Growth 137 (1994) 405.

[23] Y. Beaulieu, J.B. Webb, J.L. Brebner, J. Appl. Phys. 79 (1996) 1772.

[24] J.M. Wrobel, J.J. Dubowski, in: Z.C. Feng (Ed.), Semiconductor Interfaces and Microstructures, World Scientific Publishing, Singapore, 1992, p. 216.

[25] D.-C. Lu, X. Liu, D. Wang, L. Lin, J. Cryst. Growth 124 (1992) 383.

[26] R.M. Graham, A.C. Jones, N.J. Mason, S. Rushworth, A. Salesse, T.-Y. Seong, G. Booker, L. Smith, P.J. Walker, Semicond. Sci. Technol. 8 (1993) 1797 .

[27] R. Rousina, C. Halpin, J.B. Webb, J. Appl. Phys. 68 (1990) 2181.

[28] Z.C. Feng, S. Perkowitz, T.S. Rao, J.B. Webb, J. Appl. Phys. 68 (1990) 5363.

[29] Z.C. Feng, S. Perkowitz, R. Rousina, J.B. Webb, Can. J. Phys. 69 (1991) 386. 